\title{
Efficacy of Precut Endoscopic Mucosal Resection for Treatment of Rectal Neuroendocrine Tumors
}

\author{
Hoonsub So ${ }^{1}$, Su Hyun Yoo ${ }^{2}$, Seungbong Han ${ }^{3}$, Gwang-un Kim${ }^{1}$, Myeongsook Seo ${ }^{1}$, Sung Wook Hwang ${ }^{1}$, Dong-Hoon Yang ${ }^{1}$ and \\ Jeong-Sik Byeon ${ }^{1}$
}

Department of ${ }^{1}$ Gastroenterology, ${ }^{2}$ Pathology, Asan Medical Center, University of Ulsan College of Medicine, Seoul, ${ }^{3}$ Applied Statistics, Gachon University, Seongnam, Korea

Background/Aims: Endoscopic resection is the first-line treatment for rectal neuroendocrine tumors (NETs) measuring $<1 \mathrm{~cm}$ and those between 1 and $2 \mathrm{~cm}$ in size. However, conventional endoscopic resection cannot achieve complete resection in all cases. We aimed to analyze clinical outcomes of precut endoscopic mucosal resection (EMR-P) used for the management of rectal NET.

Methods: EMR-P was used to treat rectal NET in 72 patients at a single tertiary center between 2011 and 2015. Both, circumferential precutting and EMR were performed with the same snare device in all patients. Demographics, procedural details, and histopathological features were reviewed for all cases.

Results: Mean size of the tumor measured endoscopically was $6.8 \pm 2.8 \mathrm{~mm}$. En bloc and complete resection was achieved in 71 (98.6\%) and 67 patients (93.1\%), respectively. The mean time required for resection was $9.0 \pm 5.6 \mathrm{~min}$. Immediate and delayed bleeding developed in six (8.3\%) and 4 patients (5.6\%), respectively. Immediate bleeding observed during EMR-P was associated with the risk of delayed bleeding.

Conclusions: Both, the en bloc and complete resection rates of EMR-P in the treatment of rectal NETs using the same snare for precutting and EMR were noted to be high. The procedure was short and safe. EMR-P may be a good treatment choice for the management of rectal NETs. Clin Endosc 2017;50:585-591

Key Words: Rectum; Carcinoid tumor; Neuroendocrine tumors; Endoscopic mucosal resection

\section{INTRODUCTION}

The increasing incidence of rectal carcinoid tumors, also called well-differentiated neuroendocrine tumors (NETs) of the rectum, ${ }^{1-3}$ could be attributed to improved/higher rates of screening colonoscopy, high-resolution enhanced endoscopy, and greater awareness among endoscopists. Most rectal NETs are detected incidentally as they rarely cause carcinoid syndrome. Complete resection is the only definitive curative

Received: March 10, 2017 Revised: July 21, 2017

Accepted: August 2, 2017

Correspondence: Jeong-Sik Byeon

Department of Gastroenterology, Asan Medical Center, University of Ulsan College of Medicine, 88 Olympic-ro 43-gil, Songpa-gu, Seoul 05505, Korea Tel: +82-2-3010-3905, Fax: +82-2-476-0824, E-mail: jsbyeon@amc.seoul.kr

(cc) This is an Open Access article distributed under the terms of the Creative Commons Attribution Non-Commercial License (http://creativecommons.org/ licenses/by-nc/3.0) which permits unrestricted non-commercial use, distribution, and reproduction in any medium, provided the original work is properly cited. treatment for rectal NET. ${ }^{4}$ Because of the low risk of metastasis, based on radiological evaluation, rectal NETs measuring $<1 \mathrm{~cm}$, as well as selected tumors $1-2 \mathrm{~cm}$ in diameter are best treated using endoscopic resection in patients negative for metastasis.

Although complete resection is essential for cure, the complete resection rate of rectal NETs observed with conventional endoscopic mucosal resection (EMR) has been found to range between $52.2 \%$ and $84.6 \%{ }^{5}$ Thus, a more effective method of endoscopic resection is necessary. Although endoscopic submucosal dissection (ESD) is noted to achieve high en bloc and complete resection rates, ${ }^{6}$ this procedure is associated with a relatively high complication rate and a long procedure time, as well as the need for a long learning curve to treat rectal NETs. Therefore, in this study, we evaluated the efficacy of precut endoscopic mucosal resection (EMR-P)—a simplified procedure for the treatment of rectal NETs. 


\section{MATERIALS AND METHODS}

\section{Patients}

Endoscopic resection for rectal NET was performed in 218 patients at Asan Medical Center, between August 2011 and March 2015, with all procedures performed by two endoscopists (DHY and JSB). All patients were evaluated using abdominopelvic computed tomography and chest radiography before undergoing endoscopic resection to exclude metastases to regional lymph nodes and/or distant organs. Among these 218 patients, 68 were treated using conventional EMR, 37 using cap-assisted EMR, 30 using ESD, and 83 using EMR-P. The method used for endoscopic resection was based on the endoscopist's preference/discretion. Although there was no absolute specific indication regarding the choice of method, conventional EMR was preferred if submucosal lifting was satisfactory and secure snaring of the lesion was possible. ESD was preferred for tumors measuring $>1 \mathrm{~cm}$ in diameter. Among the 83 patients who underwent EMR-P, 11 were excluded-10 because EMR-P was performed in them for resection of remnant NET after a previous resection and one patient because of a previous history of chemoradiation therapy of the rectum. Thus, eventually 72 patients were enrolled in this study. This study was approved by the Institutional Review Board of Asan Medical Center (IRB number: 2015-0789).

\section{EMR-P procedure}

EMR-P was performed using a single-channel endo- scope (GIF-H260, GIF Q-260J, CF-H260AI, or CF-HQ290I; Olympus Medical Systems, Tokyo, Japan). Patients received a submucosal injection of $0.9 \%$ saline solution mixed with small amounts of 1:100,000 epinephrine and indigo carmine. Circumferential incision/precutting was performed using the tip of the snare (CAPTIVATOR or CAPTIVATOR II; Boston Scientific, Marlborough, MA, USA) to cut along a margin that was $2 \mathrm{~mm}$ outside the tumor. Subsequently, the snare was securely positioned in the cut groove and tightened, and the tumor was resected using electrical current (Fig. 1).

\section{Definition of terms}

Endoscopic en bloc resection of tumor was defined as onepiece resection without fragmentation of the tumor. All resected specimens were evaluated histopathologically to determine the pathological diagnosis, status of the lateral and deep resection margins, depth of invasion, and lymphovascular invasion. Each rectal NET was graded based on Ki67 index and mitotic activity according to the World Health Organization (WHO) classification. Pathology slides were reviewed, and complete resection was defined as specimens showing margins free of tumor cells, regardless of the status of lymphovascular invasion. Endoscopy images were reviewed. Procedure time was defined as the time from the beginning of submucosal injection to the completion of resection. Time spent on controlling procedure-related bleeding was included in the procedure time. Procedure-related bleeding was classified as immediate or delayed. Immediate bleeding was defined
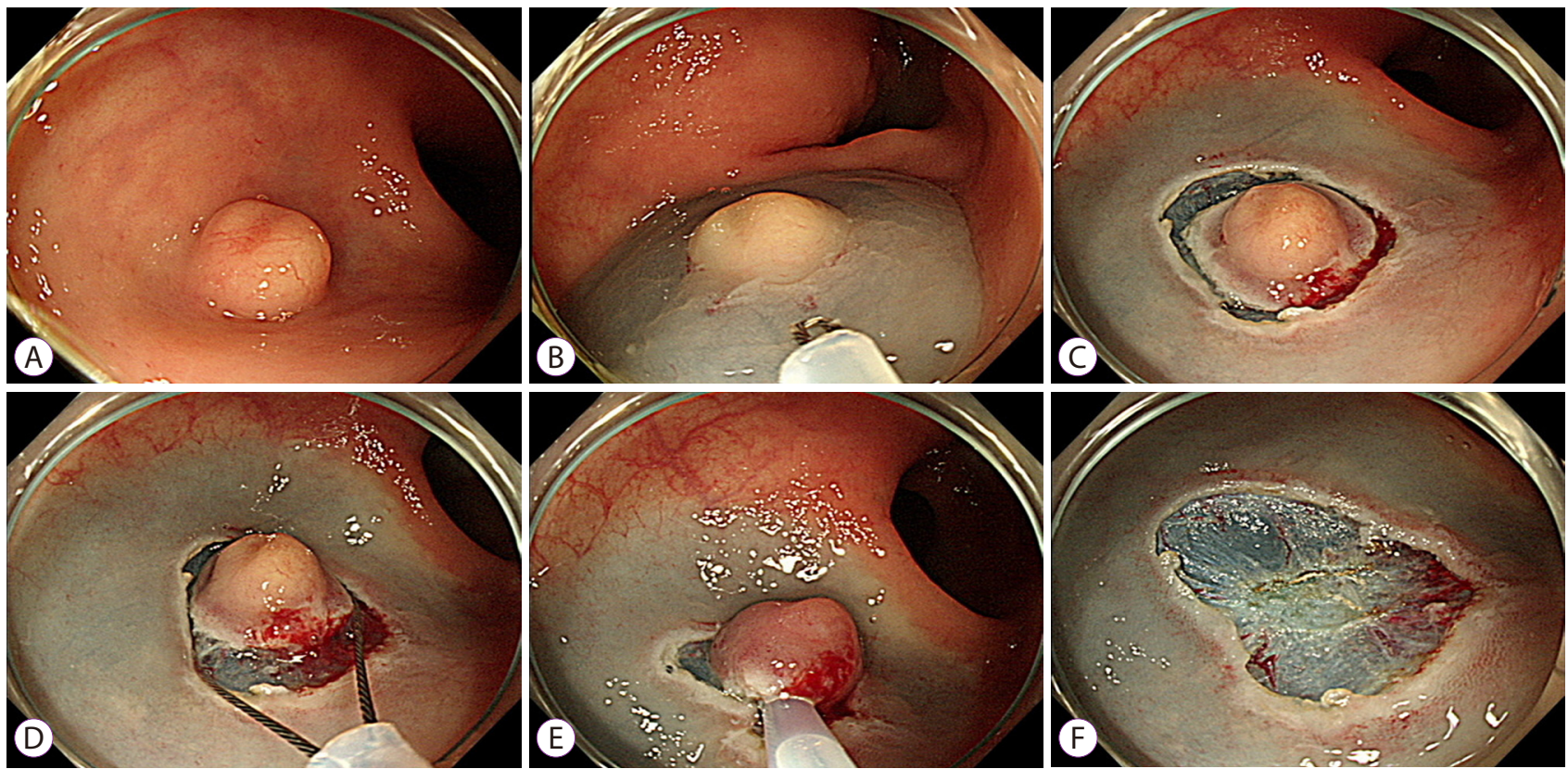

Fig. 1. Precut endoscopic mucosal resection of a rectal neuroendocrine tumor (NET). (A) A 9 mm sized rectal NET. (B) Following submucosal injection into the tumor, the tip of the snare is introduced for circumferential incision/precutting. (C) Precutting around the tumor. (D, E) Secure snaring in the precut mucosal groove. (F) A clear post-resection ulcer base is seen. 
as bleeding that developed during the procedure, which did not stop spontaneously, necessitating hemostatic interventions such as use of clips or argon plasma coagulation (APC). Delayed bleeding was defined as hematochezia, which required hemostatic interventions such as therapeutic endoscopy or angiography after completion of the EMR-P. Perforation was defined as intestinal wall penetration during the procedure or radiological detection of any extraluminal air.

\section{Outcome measures}

Primary outcomes were en bloc and complete resection rates. Secondary outcomes included procedure time and complications such as bleeding and perforation. We analyzed and investigated predictive factors for clinical outcomes such as incomplete resection and bleeding. Additionally, we reviewed literature regarding various modified EMR methods for resection of rectal NETs and compared their performance with our results.

\section{Statistical analyses}

Patient characteristics and endoscopic/histopathological results of EMR-P were summarized with mean and standard deviation (SD) for continuous variables and frequency and percentage (\%) for categorical variables. Univariate analysis was performed using the $\chi^{2}$ test or the Fisher exact test for categorical variables and the Student's $t$-test for continuous variables. In regard to incomplete resection and delayed bleeding, logistic regression was fitted to find any significant associations between clinical predictive factors. A $p$-value $<0.05$ was considered statistically significant. Data analysis was performed using IBM SPSS version 19.0 software (IBM Corp., Armonk, NY, USA) and R software version 2.13 (R Foundation for Statistical Computing, Vienna, Austria; www. r-project.org).

\section{RESULTS}

\section{Baseline characteristics}

Mean age of the 72 patients studied was $49 \pm 13$ years. Among these, 43 (59.7\%) were men. All patients had been diagnosed with rectal NET incidentally during screening colonoscopy. Most rectal NETs were located at the mid-to-distal rectum at a mean distance of $5.8 \mathrm{~cm}$ from the anal verge. Mean size of the tumor measured endoscopically was $6.8 \pm 2.8$ $\mathrm{mm}$. Baseline characteristics of enrolled patients and NETs are summarized in Table 1.

\section{Outcomes of EMR-P}

En bloc and complete resection was achieved in 71 (98.6\%) and 67 patients (93.1\%), respectively. Mean and median resec- tion times were 9.0 $\pm 5.6 \mathrm{~min}$ and $7 \mathrm{~min}$ (range, $2.5-30 \mathrm{~min}$ ), respectively. Immediate bleeding developed in six patients (8.3\%) who were successfully treated using clips or APC. Delayed bleeding developed in four patients (5.6\%) who were also treated endoscopically. None of these patients developed perforation. Although five patients showed histologically incomplete resection with positive resection margins, no additional surgery and/or endoscopic intervention was performed because endoscopically we found that complete resection had been achieved with no grossly visible residual lesion observed

Table 1. Baseline Demographic and Clinical Characteristics of Patients with Rectal NETs

\begin{tabular}{lc}
\hline Variables & All patients $(\boldsymbol{n}=\mathbf{7 2})$ \\
\hline Men, $n(\%)$ & $43(59.7)$ \\
Age $(\mathrm{yr})$, mean $(\mathrm{SD})$ & $49(13.0)$ \\
Tumor location $(\mathrm{cm})^{\text {a) }}$, mean $(\mathrm{SD})$ & $5.8(2.4)$ \\
$\begin{array}{l}\text { Endoscopically estimated size }(\mathrm{mm}), \\
\text { mean (SD) }\end{array}$ & $6.8(2.8)$ \\
$\begin{array}{l}\text { Histologically measured size }(\mathrm{mm}), \\
\text { mean }(\mathrm{SD})\end{array}$ & $6.2(2.8)$ \\
$\quad<10 \mathrm{~mm}, n(\%)$ & $63(87.5)$ \\
$\quad \geq 10 \mathrm{~mm}, n(\%)$ & $9(12.5)$ \\
Grade of NETs, $n(\%)$ & $66(91.7)$ \\
$\quad$ Grade 1 & $6(8.3)$ \\
$\quad$ Grade 2 &
\end{tabular}

NET, neuroendocrine tumor; SD, standard deviation.

${ }^{a)}$ Measured from the anal verge.

Table 2. Endoscopic and Histopathological Results of Precut Endoscopic Mucosal Resection

\begin{tabular}{lc}
\hline Variables & All patients $(\boldsymbol{n = 7 2 )}$ \\
\hline Endoscopic and histopathological results & \\
En bloc resection & $71(98.6)$ \\
Histologically complete resection & $67(93.1)$ \\
Histological margin involvement & $5(6.9)$ \\
$\quad$ Lateral & $1(1.3)$ \\
Deep & $3(4.3)$ \\
$\quad$ Both lateral and deep & $1(1.3)$ \\
Lymphovascular invasion & $3(4.3)$ \\
Procedure-related variables & \\
Resection time (min), mean (SD) & $9.0(5.6)$ \\
Immediate bleeding & $6(8.3)$ \\
Delayed bleeding & $4(5.6)$ \\
Perforation & $0(0)$ \\
\hline
\end{tabular}

Data represent $n(\%)$ or mean (SD).

$\mathrm{SD}$, standard deviation. 
Table 3. Predictive Factors for Delayed Bleeding

\begin{tabular}{|c|c|c|c|}
\hline & \multicolumn{2}{|c|}{ Delayed bleeding } & \multirow{2}{*}{$p$-value } \\
\hline & No $(n=68)$ & Yes $(n=4)$ & \\
\hline Sex & & & 0.14 \\
\hline Men, $n(\%)$ & $39(57.4)$ & $4(100)$ & \\
\hline Women, $n(\%)$ & $29(42.6)$ & $0(0)$ & \\
\hline Age (yr), mean (SD) & $48.8(13.6)$ & $47.5(9.1)$ & 0.85 \\
\hline Tumor location $(\mathrm{cm})$, mean $(\mathrm{SD})^{\mathrm{a})}$ & $5.9(2.4)$ & $4.5(1.0)$ & 0.06 \\
\hline Endoscopically estimated size $(\mathrm{cm})$ mean $(\mathrm{SD})$ & $6.9(2.80)$ & $5.0(2.16)$ & 0.19 \\
\hline Histologically measured size $(\mathrm{cm})$, mean $(\mathrm{SD})$ & $6.4(2.76)$ & $4.3(2.87)$ & 0.15 \\
\hline En bloc resection, $n(\%)$ & $67(98.5)$ & $4(100)$ & 1.00 \\
\hline Histologically complete resection, $n(\%)$ & $63(92.6)$ & $4(100)$ & 1.00 \\
\hline Resection time (min), mean (SD) & $8.7(5.07)$ & $12.9(12.27)$ & 0.55 \\
\hline Immediate bleeding, $n(\%)$ & $4(5.9)$ & $2(50.0)$ & 0.03 \\
\hline
\end{tabular}

$\mathrm{SD}$, standard deviation.

${ }^{a)}$ Measured from the anal verge.

at the post-EMR-P ulcer site. Table 2 summarizes the outcomes of EMR-P. Among 72 patients, 37 (51.4\%) underwent follow-up endoscopies during the median follow-up duration of 12.6 months (range, 3.6-49.2 months) and showed no residual tumor or local recurrence. Among the three patients who did show lymphovascular invasion, only one patient underwent additional surgery and the other two were followed-up without surgery. All these patients showed no locoregional or distant recurrence. Among the five patients with positive resection margins, four patients underwent follow-up endoscopies. No patient among these four showed local recurrence.

\section{Predictive factors for clinical outcomes}

There were no risk factors which could predict incomplete resection (data not shown). Regarding risk factors associated with delayed bleeding, the presence of immediate bleeding was the only identifiable factor that could be correlated with delayed bleeding (Table 3). Although patients demonstrating rectal NETs located in the lower rectum showed a tendency to develop delayed bleeding, this association was not statistically significant $(p=0.06)$. Logistic regression including variables such as sex, age, tumor location, tumor size, en bloc resection, resection time, and immediate bleeding was performed, and the odds ratio of immediate bleeding leading to/developing into delayed bleeding was 16.00 (95\% confidence interval, $1.76-145.12 ; p=0.01$ ).

\section{DISCUSSION}

Results from this large case series showed that EMR-P was highly effective for resection of rectal NETs, as shown by the high en bloc and complete resection rates, the acceptable procedure time, and the low complication rate. EMR-P compared well with previous studies that assessed conventional and modified EMR methods for management of rectal NET. The mechanism that explains the efficacy of EMR-P in achieving successful en bloc and complete resection is the method of creating an incision at some distance from the tumor. This increases the likelihood of negative resection margins. Moreover, EMR-P includes positioning and tightening the snare deep in the cut groove, which is created at the outset of the procedure to prevent the snare from slipping while grasping the tumor.

Although most rectal NETs are resected endoscopically, conventional EMR has been showing unsatisfactory complete resection rates, ranging between $52.2 \%$ and $84.6 \%{ }^{5}$ There is no clarity regarding the inability of conventional EMR to achieve a high complete resection rate. It could be due in part to the nature of these tumors, which originate from the lower crypts and demonstrate a subepithelial tumor-like growth pattern. Thus, modified EMR techniques have been tried to improve complete resection rates. Table 4 summarizes outcomes of modified EMR methods used in the resection of rectal NETs in previous studies and our present study. ESD, which can more effectively resect deep-seated tumors, was found to achieve an en bloc resection rate of $100 \%$ and a complete resection rate of $82.6 \%-100 \%{ }^{5-7}$ However, despite demonstrating a higher complete resection rate, the procedure time required for ESD is the longest (11.4-24.9 min) among all modified EMR methods. Additionally, ESD necessitates services of an experienced endoscopist, although ESD may be 
Table 4. Summary of the Results of Previous Studies of Endoscopic Treatment of Rectal NETs

\begin{tabular}{|c|c|c|c|c|c|c|c|}
\hline Method & Study & $\begin{array}{c}\text { No. of } \\
\text { patients }\end{array}$ & $\begin{array}{l}\text { Size }(\mathrm{cm})^{\mathrm{a})}, \\
\text { mean }(\mathrm{SD})\end{array}$ & $\begin{array}{c}\text { En bloc } \\
\text { resection, } \\
(\%)\end{array}$ & $\begin{array}{c}\text { Complete } \\
\text { resection } \\
(\%)\end{array}$ & $\begin{array}{l}\text { Procedure time (min), } \\
\text { mean }(\mathrm{SD})\end{array}$ & Complications $^{\text {b) }}$ \\
\hline \multirow[t]{5}{*}{ EMR } & Park et al. ${ }^{6}$ & 62 & $7.1(2.3)$ & 95.2 & 71.0 & $4.2(3.2)$ & $\begin{array}{l}\text { Delayed bleeding: } 0(0 \%) \\
\text { Perforation: } 1(1.6 \%)\end{array}$ \\
\hline & Lee et al. ${ }^{7}$ & 28 & $5.7(4.0)$ & 89.3 & 64.3 & $12.0(12.9)$ & None \\
\hline & Kim et al. ${ }^{10}$ & 55 & $6.5(3.2)$ & 91 & 65.5 & $5.0(0.8)$ & None \\
\hline & Zhao et al. ${ }^{11}$ & 10 & N/A & 80 & 80 & $13.4(17.13)$ & None \\
\hline & Huang et al. ${ }^{13}$ & 28 & $9(2.5)$ & 96.55 & 82.14 & 4.2 (range, $2-10)$ & None \\
\hline \multirow[t]{5}{*}{ ESD } & Park et al. ${ }^{6}$ & 31 & $6.5(2.6)$ & 100 & 90.3 & $11.4(3.7)$ & $\begin{array}{l}\text { Delayed bleeding: } 0(0 \%) \\
\text { Perforation: } 1(3.2 \%)\end{array}$ \\
\hline & Lee et al. ${ }^{7}$ & 46 & $6.2(3.1)$ & 100 & 82.6 & $18.9(7.3)$ & $\begin{array}{l}\text { Delayed bleeding: } 0(0 \%) \\
\text { Perforation: } 1(2.2 \%)\end{array}$ \\
\hline & Zhao et al. ${ }^{11}$ & 10 & N/A & 100 & 100 & $24.9(5.78)$ & None \\
\hline & Wang et al. ${ }^{12}$ & 25 & $12.27(3.73)$ & 100 & 100 & $24.79(4.89)$ & $\begin{array}{l}\text { Delayed bleeding: } 1(4.0 \%) \\
\text { Perforation: } 2(8.0 \%)\end{array}$ \\
\hline & Cheung et al. ${ }^{14}$ & 17 & $7.53(1.94)$ & 100 & 88.2 & $20.2(12.6)$ & $\begin{array}{l}\text { Delayed bleeding: } 0(0 \%) \\
\text { Perforation: } 1(5.9 \%)\end{array}$ \\
\hline \multirow[t]{2}{*}{ EMR-C } & Zhao et al. ${ }^{11}$ & 10 & N/A & 100 & 100 & $5.2(0.78)$ & None \\
\hline & Wang et al. ${ }^{12}$ & 30 & $10.35(2.95)$ & 83.3 & 70 & $9.52(2.14)$ & None \\
\hline \multirow[t]{2}{*}{ EMR-L } & Mashimo et al. ${ }^{9}$ & 61 & $6.4(2.4)$ & $\mathrm{N} / \mathrm{A}$ & 95.2 & $\mathrm{~N} / \mathrm{A}$ & $\begin{array}{l}\text { Delayed bleeding: } 1(1.6 \%) \\
\text { Perforation: } 0(0 \%)\end{array}$ \\
\hline & Kim et al. ${ }^{10}$ & 45 & $5.8(2.4)$ & 100 & 93.3 & $4.8(0.9)$ & $\begin{array}{l}\text { Delayed bleeding: } 1(2.2 \%) \\
\text { Perforation: } 0(0 \%)\end{array}$ \\
\hline \multirow[t]{3}{*}{ EMR-P } & Huang et al. ${ }^{13}$ & 31 & $9(2.5)$ & 100 & 96.7 & 7.6 (range, 5-13) & None \\
\hline & Cheung et al. ${ }^{14}$ & 16 & $6.63(1.99)$ & 87.5 & 81.2 & $9.69(3.61)$ & $\begin{array}{l}\text { Delayed bleeding: } 0(0 \%) \\
\text { Perforation: } 1(6.3 \%)\end{array}$ \\
\hline & This study & 72 & $6.2(2.8)$ & 98.6 & 93.1 & $9.0(5.6)$ & $\begin{array}{l}\text { Delayed bleeding: } 4(5.6 \%) \\
\text { Perforation: } 0(0 \%)\end{array}$ \\
\hline
\end{tabular}

Data reported as (\%), mean (SD) or median (range).

NET, neuroendocrine tumor; SD, standard deviation; EMR, endoscopic mucosal resection; ESD, endoscopic submucosal dissection; EMR-C, cap-assisted EMR; EMR-L, EMR using band ligation; EMR-P, precut endoscopic mucosal resection; N/A, not available.

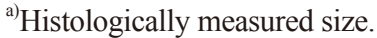

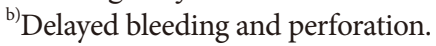

easier to perform for management of rectal NETs compared to the management of large colorectal neoplasms in the proximal colon. We propose that the ESD procedure utilized for the management of rectal NETs should be utilized to train endoscopists intending to perform colorectal ESD. ${ }^{6}$ We suggest that ESD may be examined/assessed as a good treatment option for the management of rectal NETs when ESD specialists or experienced ESD trainees who want to improve their ESD skills are available.

Other modified EMR methods, including cap-assisted EMR and EMR using band ligation, have been suggested as treatment options for rectal NETs. ${ }^{8}$ These methods, while demonstrating complication rates as low as those of conventional EMR, have been shown to achieve higher complete resection rates (70\%-100\%) compared to conventional EMR (64.3\%-82.1\%). Their procedure time was acceptable, ranging between $4.8 \mathrm{~min}$ and $9.52 \mathrm{~min}$ (Table 4). These methods were as effective and safe as EMR-P, suggesting that any of these modified EMR methods, including EMR-P, can be utilized to resect rectal NETs, and that the selection of procedure is solely at the discretion of the endoscopist.

Our study showed that EMR-P has several advantages over other related procedures: (1) Unlike cap-assisted EMR and EMR using band ligation, which require additional accessories such as cap and ligating devices, respectively, EMR-P does not require any additional instruments because precutting is performed using the snare tip. ${ }^{9,10}$ (2) Unlike cap-assisted EMR, which is limited in terms of tumor size that can be resected 
because the tumor must be aspirated through the cap, EMR-P has no such size limitation with respect to tumor resection. ${ }^{11,12}$

Two previous studies have investigated the usefulness of EMR-P for resection of rectal NET. ${ }^{13,14}$ These studies, which enrolled 31 and 16 patients, respectively, showed complete resection rates of $96.7 \%$, and $81.2 \%$, respectively, which are comparable to the complete resection rate of $93.1 \%$ demonstrated in this present study. These findings indicate that EMR-P is a highly effective endoscopic resection method for the management of rectal NETs. Moreover, EMR-P was found to be safe because no patient demonstrated perforation. Although delayed bleeding did occur, all patients who developed delayed bleeding could be managed endoscopically. Additionally, immediate bleeding was noted to be a predictive factor for the development of delayed bleeding in our present study, as was found in previous reports that describe risk factors for delayed bleeding after EMR of gastric or colorectal polyps. ${ }^{15-17}$ Thus, it is recommended that endoscopists should pay more attention in patients showing immediate bleeding after EMR-P of rectal NET to reduce the risk of delayed bleeding. Furthermore, the post-resection ulcer can be observed over a longer duration of time such as approximately 5 min to assess and control any visible vessels, which are more likely to be noticed after $5 \mathrm{~min}$ than within 1-3 min after colonic EMR. ${ }^{18}$

A strength of our EMR-P method compared to previous studies describing EMR- $\mathrm{P}^{13,14}$ was our use of the snare tip rather than specialized endoknives for precutting. Use of the snare tip reduced the time and cost of this procedure, because additional accessories did not have to be introduced and withdrawn before snaring. To the best of our knowledge, ours is the largest study series evaluating the efficacy of EMR-P for the management of rectal NETs using a single snare device without the need for further knives, which confirms the clinical usefulness of this method in clinical practice.

Limitations of our study: (1) Ours was a retrospective analysis, and selection of the endoscopic resection method used was at the discretion of each endoscopist, which may have resulted in selection bias. However, selection bias was likely not very significant because selection of the endoscopic resection method was not based on any predefined absolute criteria. Additionally, EMR-P was performed in relatively difficult cases, because conventional EMR was generally used when submucosal lifting was satisfactory and secure snaring of the lesion was possible as described previously. Thus, it is possible to infer that EMR-P demonstrated a good performance, based on our study results. (2) Only 51.4\% of enrolled patients underwent follow-up endoscopies, and verifying prognosis after EMR-P in this small number of cases who did undergo follow-up endoscopies was difficult. Thus, studies with a greater number of patients are necessary to confirm the accuracy of our follow-up results. (3) The median follow-up period of this study was only 12.6 months. Thus, we could not investigate patients over a long-term follow-up duration to assess local or distant recurrence. However, previous studies describe excellent long-term outcomes after endoscopic resection of rectal NETs $\leq 10 \mathrm{~mm}$ with no recurrence or metastasis noted in any patient after a median duration of 31 months, regardless of resection margin status. ${ }^{19}$ In that study, most patients (107/109) underwent conventional EMR, and the complete resection rate was only $49.5 \% .^{19}$ Because our study showed a higher complete resection rate, we reason that prognosis would be excellent, although long-term outcomes were not analyzed directly.

In conclusion, EMR-P using the snare tip for precutting and the same snare for EMR is a highly effective method for resection of rectal NETs, showing high en bloc and complete resection rates, a short procedure time, and an acceptable safety profile without additional costs.

\section{Conflicts of Interest}

The authors have no financial conflicts of interest.

\section{REFERENCES}

1. Hauso O, Gustafsson BI, Kidd M, et al. Neuroendocrine tumor epidemiology: contrasting Norway and North America. Cancer 2008;113:26552664.

2. Gastrointestinal Pathology Study Group of Korean Society of Pathologists, Cho MY, Kim JM, et al. Current trends of the incidence and pathological diagnosis of gastroenteropancreatic neuroendocrine tumors (GEP-NETs) in Korea 2000-2009: multicenter study. Cancer Res Treat 2012;44:157-165.

3. Kim BC, Park CH, Kim TI, et al. Variable clinical classifications and diagnostic coding systems of colorectal neuroendocrine tumor. Intest Res 2013;11:14-22.

4. Caplin M, Sundin A, Nillson O, et al. ENETS consensus guidelines for the management of patients with digestive neuroendocrine neoplasms: colorectal neuroendocrine neoplasms. Neuroendocrinology 2012;95:8897.

5. Zhong DD, Shao LM, Cai JT. Endoscopic mucosal resection vs endoscopic submucosal dissection for rectal carcinoid tumours: a systematic review and meta-analysis. Colorectal Dis 2013;15:283-291.

6. Park HW, Byeon JS, Park YS, et al. Endoscopic submucosal dissection for treatment of rectal carcinoid tumors. Gastrointest Endosc 2010;72:143-149.

7. Lee DS, Jeon SW, Park SY, et al. The feasibility of endoscopic submucosal dissection for rectal carcinoid tumors: comparison with endoscopic mucosal resection. Endoscopy 2010;42:647-651.

8. Choi HH, Kim JS, Cheung DY, Cho YS. Which endoscopic treatment is the best for small rectal carcinoid tumors? World J Gastrointest Endosc 2013;5:487-494

9. Mashimo Y, Matsuda T, Uraoka T, et al. Endoscopic submucosal resection with a ligation device is an effective and safe treatment for carcinoid tumors in the lower rectum. J Gastroenterol Hepatol 2008;23:218-221.

10. Kim HH, Park SJ, Lee SH, et al. Efficacy of endoscopic submucosal resection with a ligation device for removing small rectal carcinoid tumor compared with endoscopic mucosal resection: analysis of 100 cases. Dig Endosc 2012;24:159-163. 
11. Zhao ZF, Zhang N, Ma SR, et al. A comparative study on endoscopy treatment in rectal carcinoid tumors. Surg Laparosc Endosc Percutan Tech 2012;22:260-263.

12. Wang X, Xiang L, Li A, et al. Endoscopic submucosal dissection for the treatment of rectal carcinoid tumors 7-16 mm in diameter. Int J Colorectal Dis 2015;30:375-380.

13. Huang J, Lu ZS, Yang YS, et al. Endoscopic mucosal resection with circumferential incision for treatment of rectal carcinoid tumours. World J Surg Oncol 2014;12:23.

14. Cheung DY, Choi SK, Kim HK, et al. Circumferential submucosal incision prior to endoscopic mucosal resection provides comparable clinical outcomes to submucosal dissection for well-differentiated neuroendocrine tumors of the rectum. Surg Endosc 2015;29:1500-1505.

15. Okano A, Hajiro K, Takakuwa H, Nishio A, Matsushita M. Predictors of bleeding after endoscopic mucosal resection of gastric tumors. Gastro- intest Endosc 2003;57:687-690.

16. Burgess NG, Metz AJ, Williams SJ, et al. Risk factors for intraprocedural and clinically significant delayed bleeding after wide-field endoscopic mucosal resection of large colonic lesions. Clin Gastroenterol Hepatol 2014;12:651-661.e1-e3.

17. Kim HS, Kim TI, Kim WH, et al. Risk factors for immediate postpolypectomy bleeding of the colon: a multicenter study. Am J Gastroenterol 2006;101:1333-1341.

18. Jung Y, Chung IK, Cho YS, et al. Do we perform a perfect endoscopic hemostasis prophylactically with argon plasma coagulation in colonic endoscopic mucosal resection? Dig Dis Sci 2015;60:3100-3107.

19. Kim GU, Kim KJ, Hong SM, et al. Clinical outcomes of rectal neuroendocrine tumors $\leq 10 \mathrm{~mm}$ following endoscopic resection. Endoscopy 2013;45:1018-1023. 